\title{
COVID-19 Face Masks as a Long-Term Source of Microplastics in Recycled Urban Green Waste
}

Dirk H. R. Spennemann (1)

Citation: Spennemann, D.H.R. COVID-19 Face Masks as a

Long-Term Source of Microplastics in Recycled Urban Green Waste. Sustainability 2022, 14, 207. https:/ / doi.org/10.3390/su14010207

Academic Editor: John Rennie Short

Received: 24 November 2021

Accepted: 18 December 2021

Published: 26 December 2021

Publisher's Note: MDPI stays neutral with regard to jurisdictional claims in published maps and institutional affiliations.

Copyright: (C) 2021 by the author. Licensee MDPI, Basel, Switzerland. This article is an open access article distributed under the terms and conditions of the Creative Commons Attribution (CC BY) license (https:// creativecommons.org/licenses/by/ $4.0 /)$.
Institute for Land, Water and Society, Charles Sturt University, P.O. Box 789, Albury, NSW 2640, Australia; dspennemann@csu.edu.au

\begin{abstract}
Following the outbreak of the COVID-19 pandemic in March 2020, many governments recommended or mandated the wearing of fitted face masks to limit the transmission of the SARS$\mathrm{CoV}-2$ virus via aerosols. Concomitant with the extensive use of non-sterile, surgical-type single-use face masks (SUM) was an increase of such masks, either lost or discarded, in various environmental settings. With their low tensile strength, the spunbond and melt-blown fabrics of the SUM are prone to shredding into small pieces when impacted by lawn cutting equipment. Observations highlight the absence of smaller pieces, which are either wind-dispersed or collected by the mower's leaf catcher and disposed together with the green waste and then enter the municipal waste stream. As proof-of-concept, experiments using a domestic lawn-mower with different height settings and different grass heights, show that $75 \%$ of all pieces of SUM fabric caught in the catcher belonged to sizes below $10 \mathrm{~mm}^{2}$, which under the influence of UV light will decay into microfibers. The implications of SUM generated microplastics are discussed.
\end{abstract}

Keywords: COVID-19; personal protective equipment; face masks; littering; municipal waste management; green waste; microplastics

\section{Introduction}

Soon after COVID-19, the respiratory disease caused by the SARS-CoV-2 coronavirus [1], rapidly developed into a global pandemic in early 2020, many governments at national or state levels enacted public health measures to curb or at least slow the progress of COVID-19. Given that SARS-CoV-2 is primarily transmitted via aerosols emitted while breathing, coughing, or sneezing [2,3], many governments have mandated, or at least recommended, the wearing of fitted face masks [4-7].

Until COVID-19, the use of face masks was restricted to specific professions and activities: sterile, single-use surgical-type masks used by the medical profession (Figure 1, Figures S1 and S2, Supplementary Materials); disposable KN95/P2 type masks (with and without valves) used in the construction industry to filter low levels of dust and paint fumes; and full face masks with exchangeable air filters for more hazardous work [8-10]. In non-professional settings, face masks were worn only in a number of East Asian countries, a practice spurred by the SARS-CoV-1 epidemic of 2003. [11].

The high demand for face masks during the COVID-19 pandemic led to a rapidly expanded production and use of non-sterile, surgical-type single-use face masks (henceforth: SUM), the majority of which is sourced from Chinese manufacturers (Figures S1 and S2, Supplementary Materials) [12]. Since these are far more common than washable masks from cotton and other fabrics (see below), they soon posed environmental issues. The quantity of masks manufactured is staggering, with China exporting more than 200 billion masks in 2020 alone [13]. 


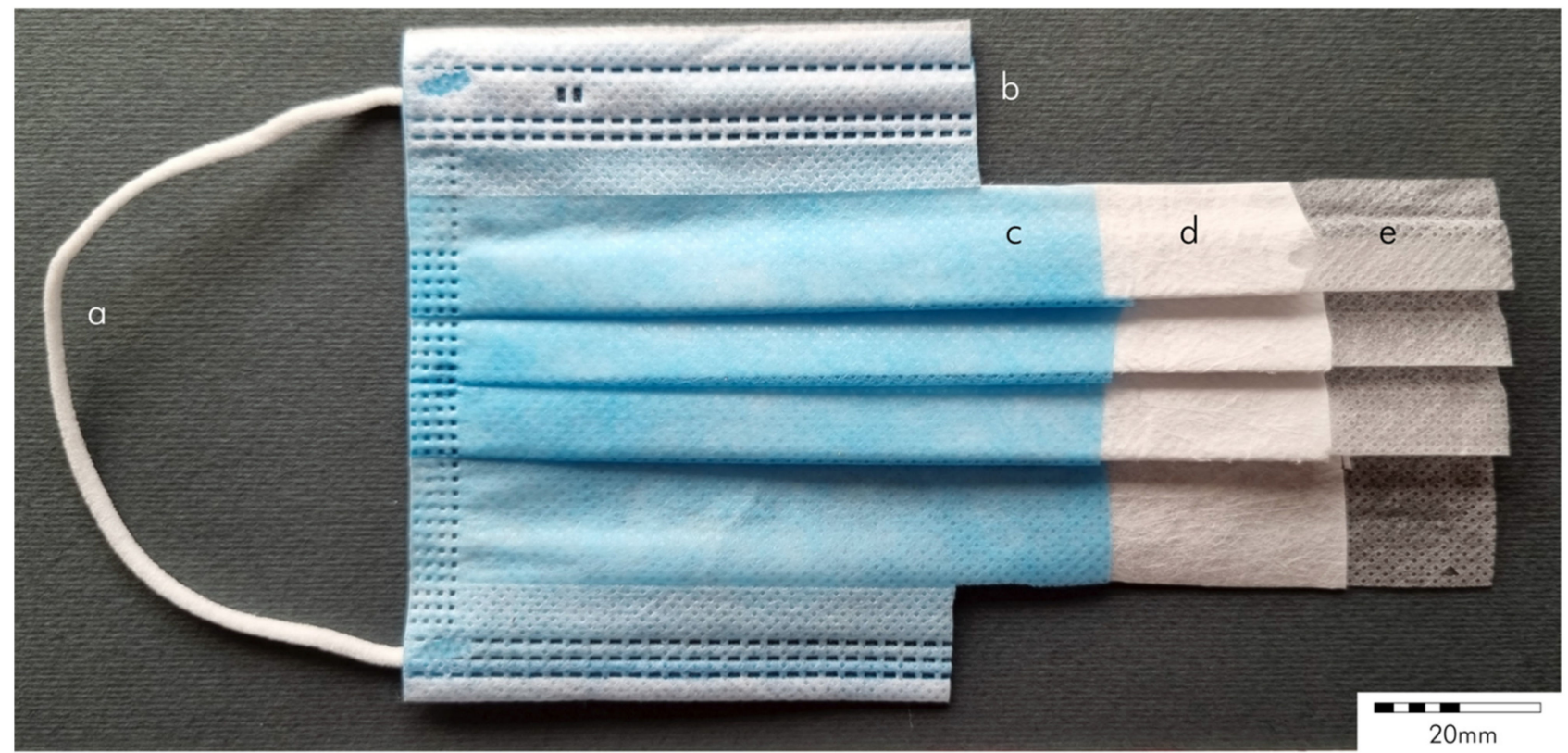

Figure 1. Components of a surgical-type single-use face mask. (a) Elastic ear loop; (b) heat-wielded seam; (c) outer layer of spunbond polypropylene fabric; (d) central core of melt-blown polypropylene fabric; (e) inner layer of spunbond polypropylene fabric.

\subsection{Manufacture and Composition of Surgical-Type Single-Use Masks}

Single-use masks are manufactured from a nonwoven fabric created from polymers with thermoplastic behavior, primarily polypropylene, by a spunbond or melt blowing process [14]. This processes, which randomly deposit micro- and nanofibers to create nonwoven sheets, allows for the creation of fabric of varied densities and thickness (Figure 2, Figures S3 and S4, Supplementary Materials) [15]. The masks are usually made as 3-ply, using fabrics of different density, with the (usually) blue or green colored fluid-repellent layer worn outwards and a white absorbent layer worn in the center and another fluidrepellent layer (usually white) worn inwards (Figures 1 and 2; Figures S1 and S2) [16]. The characteristics of nonwoven fabrics are that they can be dense, but because they are essentially matted fibers, they have a low tensile strength.

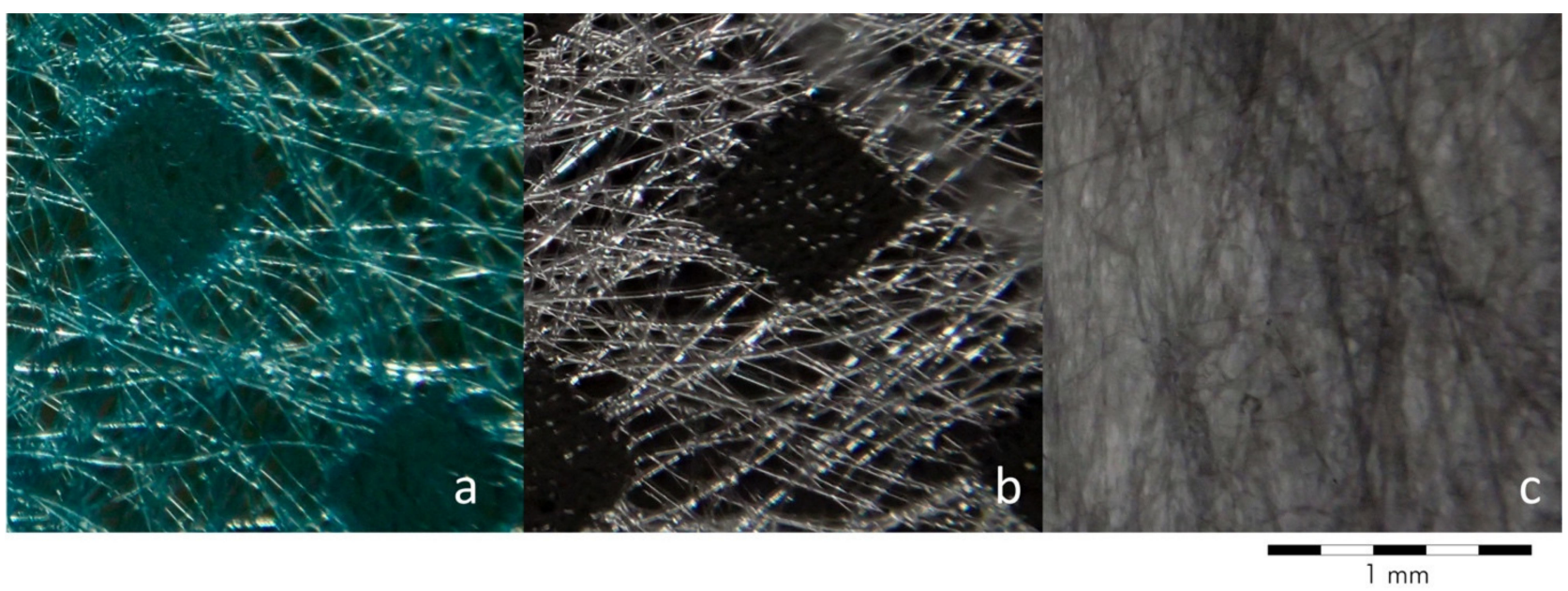

Figure 2. Fabric used for a surgical-type single-use face mask. (a) Outer layer of spunbond polypropylene; (b) inner layer of spunbond polypropylene; (c) central core of melt-blown polypropylene fabric. 


\subsection{Biodegradation of Surgical-Type Single-Use Masks}

While exposure to dry heat at natural environmental levels $\left(<70^{\circ} \mathrm{C}\right)$ or exposure to hot water has no observable effect on the tensile strength of polypropylene fibers $[17,18]$, prolonged outdoor exposure to ultra-violet light and visible light intensity, combined with temperature variations due to thermal expansion and contraction, cause a decrease in tensile strength, separation of individual fibers and eventual breakdown of the fibers through photo-oxidation into smaller fragments [19-23] and eventually micro-plastics through brittle fracturing [24]. In addition, since the bonding strength of the extruded spunbond or melt-blown fibers to each other is less than the strength of the fiber itself, continued cycles of thermal expansion and contraction result in fiber separation before fiber breakdown. Biodegradation is accelerated if the fabric is further exposed to mechanical impact, such as movement in water [22] or treadage.

Experimental studies of fabrics buried in soil have shown that spunbond and meltblown fabric made from polypropylene does not decay or lose its strength, while fabric made from raw cotton, Rayon or polylactic acid (PLA) does biodegrade [25]. Other studies also showed that polypropylene plastics do not decay at measurable rates when buried [26]. Consequently, once buried, SUM fabric will decay considerably slower than when exposed to the open environment, with the decay, if any, affecting the bonding strength between the fibers. The decay processes of fabric made from polypropylene will resume once they are exposed again to ultra-violet light.

\subsection{General Environmental Concerns}

Soon after the wearing of face masks become recommended or mandated, environmental concerns emerged about their impact on the global plastic waste footprint [27], as surgical-type single-use masks began to appear as hard waste both in municipal rubbish disposal [28-30] and as stray items of litter in natural settings (Figure S5) [31]. While much attention was paid to SUM in marine environments in terms of general pollution [32,33], nano- and microplastics [34-36], and the physical impact on wildlife [37-39], little work has been carried out on the impact of discarded SUM in urban environments.

It is common to observe larger fragments of SUM that have been run over, and shredded by landscaping machinery, such as slashers and lawn mowers (Figure 3 and Figures S6-S13). In many cases, smaller fragments seem to be missing, suggesting that they were removed from the site together the lawn clippings, and would have entered the waste stream.

This paper will examine, by way of observations and experiments, the impact of SUM being run over by grass cutting machinery and will consider the fate and future impact of discarded SUM that may have ended up in urban green waste which is collected for composting and subsequent re-use in landscaping. It will show that the long-term impact of SUM-derived polypropylene fabric may be underestimated, if not unrecognized altogether, by urban planners. 

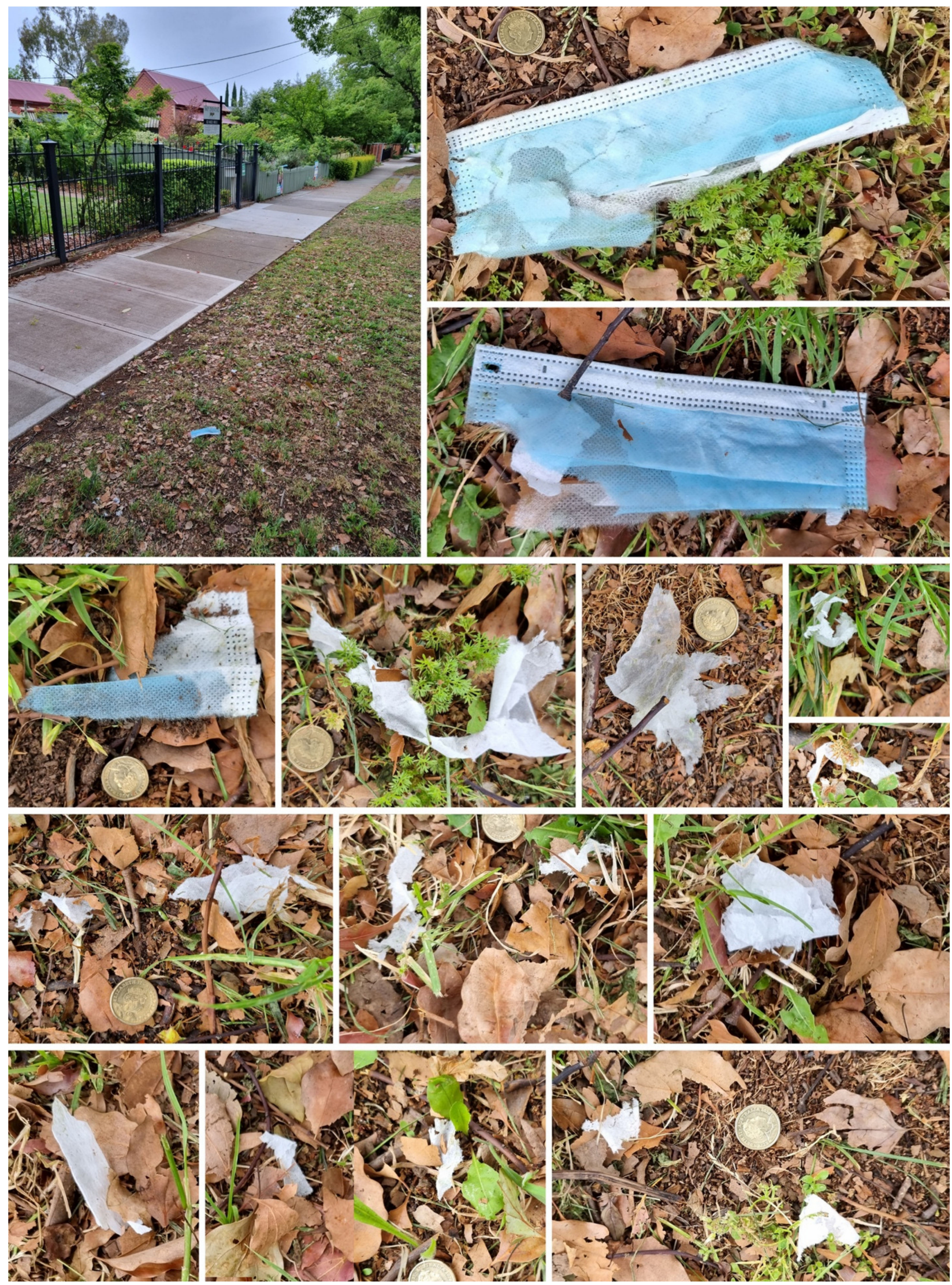

Figure 3. Example of a shredded disposable mask on a suburban roadside verge mowed by the owner without the use of a leaf catcher (Albury, NSW). The coin has a diameter of $20 \mathrm{~mm}$. 


\section{Field Observations}

As part of a project assessing the cultural heritage aspects of COVID-19 [40], the author conducted a longitudinal survey of face masks encountered on the ground in Albury, a regional community in New South Wales, most populous state [41]. Both the observations of actual face mask use [42,43] and the documentation of intentionally discarded or lost masks encountered on the ground [44] have shown that in Australia disposable surgicaltype face masks are far more common than washable and reusable fabric masks. The overwhelming majority of disposable single use masks encountered in Australia are of the three-layered surgical type [42-44].

While the majority of masks was found on the streets and car parks, lost or intentionally discarded when exiting vehicles (Figure S17) [44], numerous masks ended up in creek lines or were washed into gutters and stormwater drains (Figure S5).

Due to their light weight, disposable surgical-type face masks are also very susceptible to air movement, be it natural wind or draft caused by fast-moving vehicles. Consequently, numerous masks were found to have been blown onto roadside verges, where they remained until either covered by leaf litter, or until they were caught up in landscaping processes such as vegetation slashing or mowing (Figure 3).

Unlike similar debris, such as chip packets or candy wrappers, SUM are made from spunbond and melt-blown fabric, which readily splits and tears when subjected to force, not only shredding to pieces of varied size, but also generating a plethora of separated fibers. Observations repeatedly encountered larger fragments of shredded SUM, usually the thicker and denser sections along the heat-wielded seams (Figure 3, Figures S6-S8 and S10-S12).

In most instances the smaller fragments seemed to be lacking (or were not obvious), which suggests that they ended up with grass clippings in the leaf catcher of the mower. In addition, because of their smaller size, coupled with their light weight, they are more easily dispersed by wind than the larger sections, suggesting that pollution with polypropylene fabric may affect an area well beyond the immediate shredding location.

\section{Experimental Data}

To validate the field observations, a three-part proof of concept experiment was designed.

\subsection{Methodology}

The experiment was carried out on the lawn of a suburban backyard in Albury, using a domestic lawn mower (Victa 18V $37 \mathrm{~cm}$ model 2691646), which in size and design is representative of privately-owned push mowers used to mow the nature strips (roadside verges) in front of people's houses. For the experiment, single-use non-sterile, surgical-type face masks were used which came from a bulk pack of 50 masks manufactured in March 2020 by Shandong Shengningkang Medical Supplies Co., Dezhaou City, Shandong, China (Figure 1 and Figures S1 and S2). As noted, these types of masks are by far the most common type of disposable masks (only 1.2\% of masks worn are KN95 type masks). These pleated masks are 3-ply, with spunbond polypropylene as the inner and outer layer of and a central core of melt-blown polypropylene (Figure 2). The masks had been kept in a cupboard in the original box until needed and had not been exposed to ultraviolet light.

For the experiment a disposable surgical face mask was fitted to the face of the investigator, with the nose wire adjusted to ensure a tight fit. That mask was then placed on the lawn and run over with the lawn mower travelling in a straight line (Figure S18). All lawn clippings caught in the leaf catcher were bagged, while all macroscopically visible pieces of the mask that were left on the lawn were photographed and collected. The white and light blue coloring of the mask fragments made it easy to identify them against the lush green background of the lawn. That experiment was repeated twice with different settings of the height of the cutting blade above the ground and the length of the lawn 
grass (Table 1). After each experiment, the leaf catcher was inspected for any residual macroscopically visible pieces of the mask and was cleaned out (blown out with air) to prevent cross-contamination between experiments.

The bagged lawn clippings were airdried, sorted on a dark-colored metal tray (to make the pieces of white and light blue fabric stand out) and all macroscopically visible pieces of the mask were extracted with laboratory tweezers. No attempt was made to screen the clippings under high magnification to extract microfibers. The pieces were then classified, sorted by size (Figures 4 and 5, Figures S19-S24)) and tabulated (Table 1).

Table 1. Experimental settings and outcomes.

\begin{tabular}{|c|c|c|c|c|c|c|}
\hline & \multicolumn{6}{|c|}{ Experiment } \\
\hline Design & \multicolumn{2}{|c|}{$\mathbf{A}$} & \multicolumn{2}{|c|}{ B } & \multicolumn{2}{|c|}{$\mathrm{C}$} \\
\hline Grass height & \multicolumn{2}{|c|}{$4-5 \mathrm{~cm}$} & \multicolumn{2}{|c|}{$7-8 \mathrm{~cm}$} & \multicolumn{2}{|c|}{$7-8 \mathrm{~cm}$} \\
\hline Mower setting & \multicolumn{2}{|c|}{2} & \multicolumn{2}{|c|}{4} & \multicolumn{2}{|c|}{6} \\
\hline Cutting Blade Height & \multicolumn{2}{|c|}{$3 \mathrm{~cm}$} & \multicolumn{2}{|c|}{$4.5 \mathrm{~cm}$} & \multicolumn{2}{|c|}{$6 \mathrm{~cm}$} \\
\hline \multicolumn{7}{|l|}{ Results } \\
\hline particle size (square) & lawn & catcher & lawn & catcher & lawn & catcher \\
\hline$<5 \mathrm{~mm}$ & 3 & 1 & $\mathrm{i}$ & 39 & 7 & 19 \\
\hline 5-10 mm & 5 & 3 & 4 & 24 & 9 & 7 \\
\hline $10-15 \mathrm{~mm}$ & - & 4 & 2 & 8 & 1 & 4 \\
\hline $15-20 \mathrm{~mm}$ & - & - & 1 & 6 & 2 & - \\
\hline $20-50 \mathrm{~mm}$ & - & - & - & 2 & - & 3 \\
\hline $50-100 \mathrm{~mm}$ & - & - & 1 & 2 & 1 & 1 \\
\hline$>100 \mathrm{~mm}$ & - & 1 & - & 1 & - & 1 \\
\hline string & - & - & - & 2 & 1 & 1 \\
\hline Total pieces & 8 & 9 & 8 & 84 & 21 & 36 \\
\hline
\end{tabular}

\subsection{Results}

The three experiments produced very different types of debris, both the debris remaining on the lawn after each mow and that collected in the leaf catcher. The total number of retrieved pieces, left on the lawn and those caught in the catcher, ranged from 17 in experiment A to 92 in experiment B. Setting aside the large section of the mask which survived in each of the experiments (Figure 4), as well as the elastic ear loop strings, all but one of the retrieved pieces derived from the melt-blown central filter fabric (Figure 5). When the samples were sorted, it was noted that one of the ear loop strings for sample A was missing. During the mowing, the impact of the mask was the strongest in that experiment, suggesting that the loop may have been ripped off and thrown well beyond the recovery zone.

Between $75 \%$ and $77.7 \%$ of pieces derived from the melt-blown central filter fabric belong to the sizes below $10 \mathrm{~mm}^{2}$. Among experiment B and C, between $43.8 \%$ and $48.1 \%$ of these pieces were of sizes below $5 \mathrm{~mm}^{2}$. It is certain that pieces of sub $1 \mathrm{~mm}^{2}$ size will have been missed on the lawn, and possibly even among the clippings collected in the catcher. They might have escaped detection, especially if they adhered to the back of grass clippings.

The large piece of mask collected by the leaf catcher during experiment C (Figure 4) well illustrates that the tensile strength of melt-blown fabric is significantly less than that of spunbond fabric. While both are torn quite significantly, both the inner and outer spunbond layer are complete, whereas the inner filter layer of melt-blown fabric is shredded-even the sections that still remain between the sheets of spunbond fabric (Figure 4). No search was carried out for single fibers or microplastics. Close-up photography shows the frayed edges of both spunbond and melt-blown fabric (Figures 6 and 7). Using tweezers, single fibers could be readily separated from the shredded fabric remains (Figures 8 and 9). Spunbond fibers, with a diameter of 20 micron are longer 
and more entangled with other fibers, while the fibers of melt-blown fabric are not only thinner (15 micron), but are also much shorter and matted, rather than entangled. In consequence, the tensile strength of melt-blown fabric is higher, with mechanical impacts causing rapid disintegration into microfibers.

The differences between the three experiments are considerable. The fewest pieces were generated with a short lawn and a low mower setting (Table $1(\mathrm{~A})$ ). In that experiment the mask was captured by the blade and thrown straight (and audibly) into the catcher which effectively reduced its exposure to the mower blade spinning at $3700 \mathrm{rpm}$. The largest number of fragments was generated at the intermediate setting (Table 1 (B)) where the mask was exposed for a prolonged period, shredding it, while the intermediate mower setting generated a vortex that dragged most pieces into the catcher. The highest setting generated a large number of pieces on both in the catcher and on the lawn (Table 1 (C)). Here the spinning blade shredded the mask, but the high setting had the effect of a reduced vortex, ensuring that mask fragments would be caught and retained in-between the leaves of the lawn.

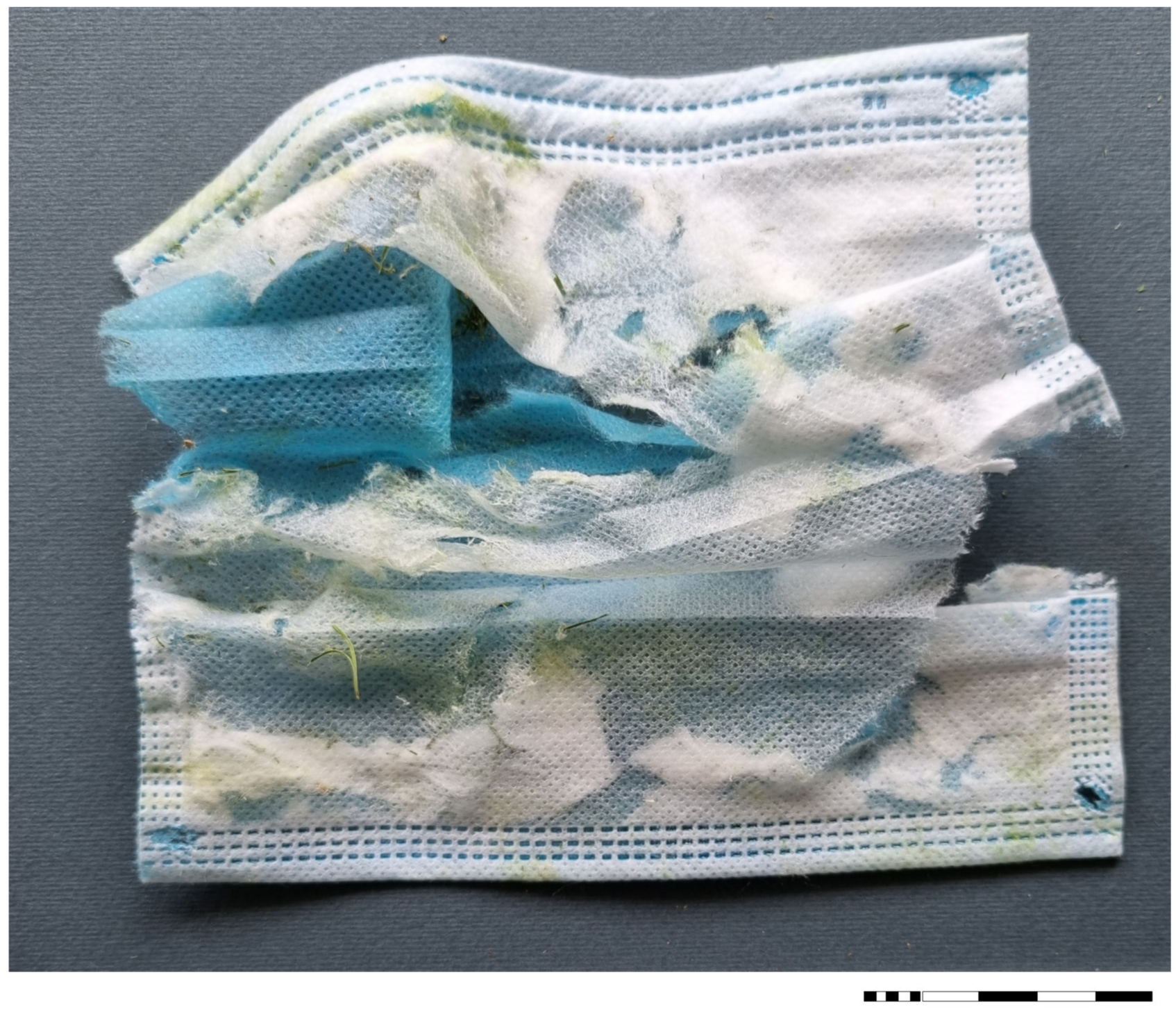

$50 \mathrm{~mm}$

Figure 4. Example of the remains of an experimentally shredded disposable mask (experiment C). For the other size of the mask, see Figure S21. 

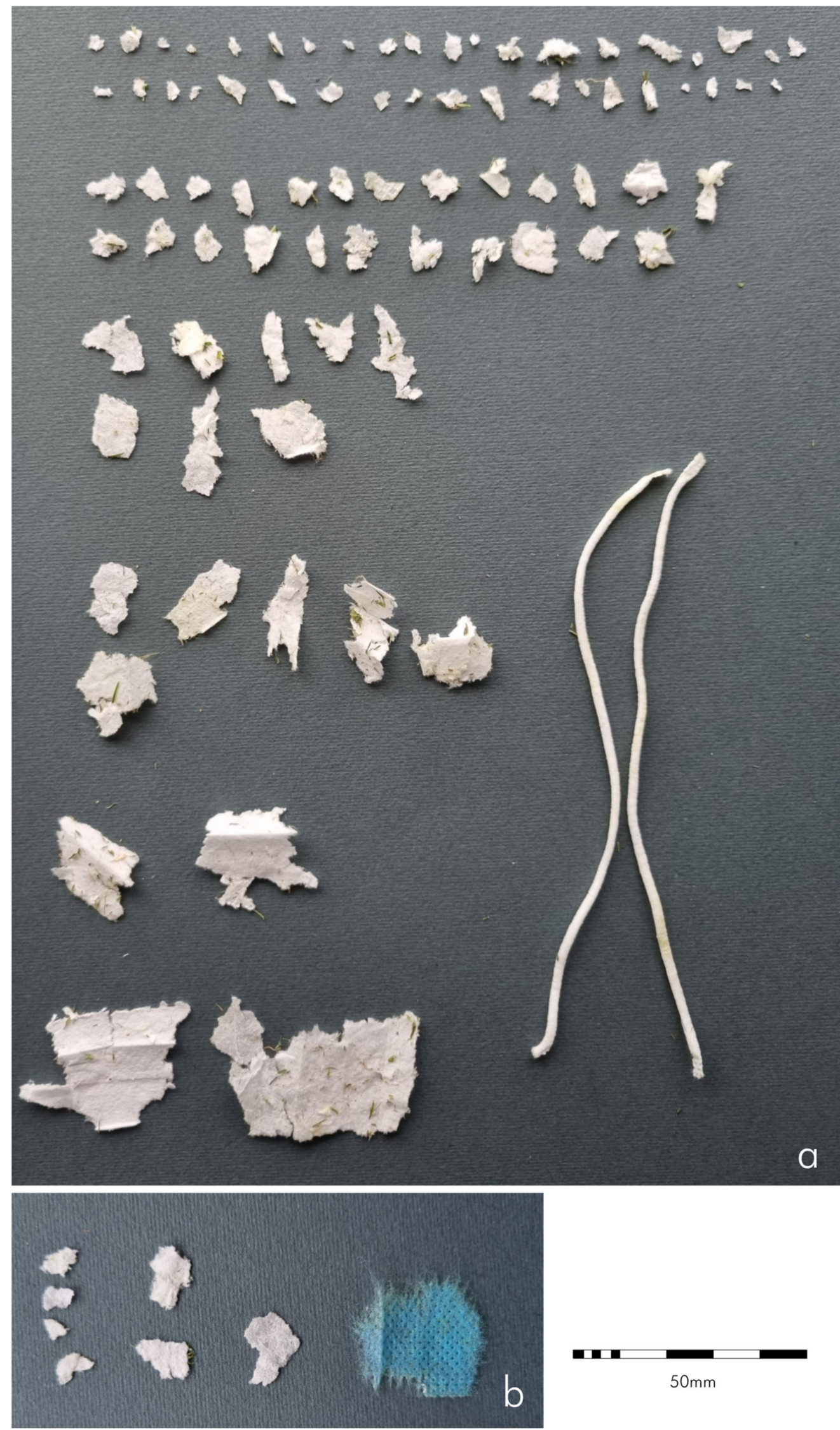

Figure 5. Fragments of an experimentally shredded disposable mask (experiment B). (a) Ppieces in catcher; (b) pieces on lawn. 


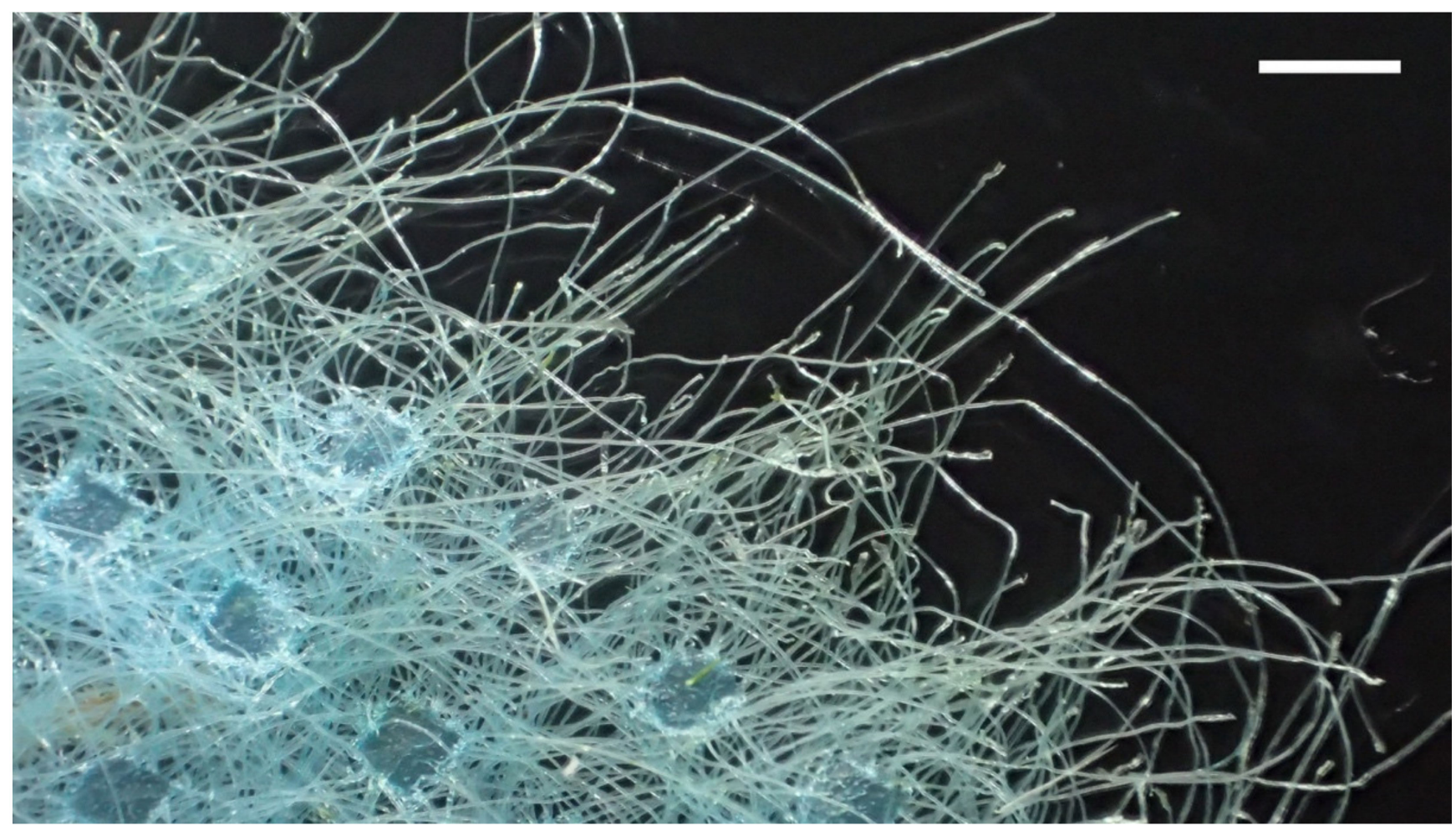

Figure 6. Detail of shredded spunbond fabric. Experiment B. The white bar indicates $1 \mathrm{~mm}$.

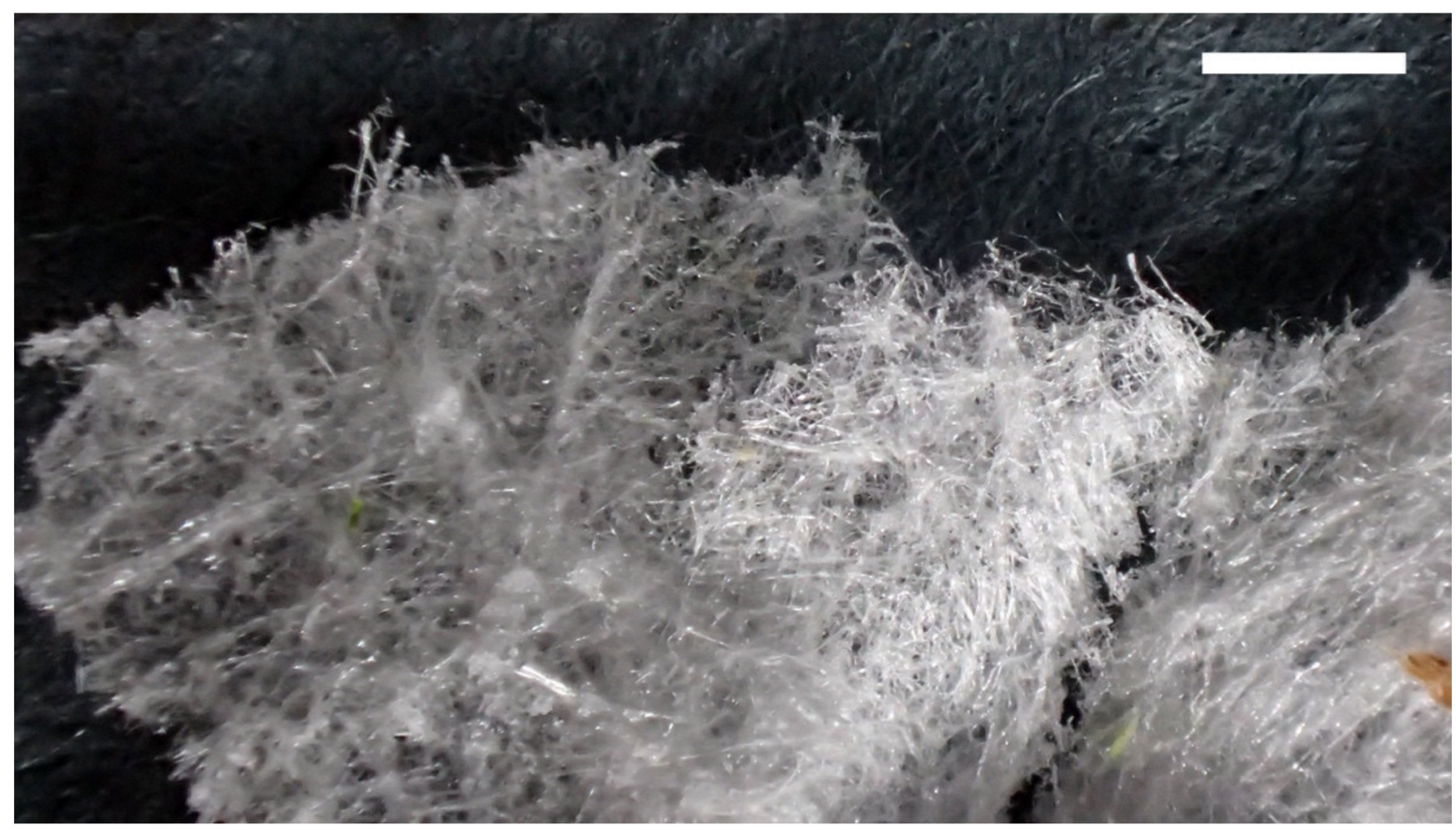

Figure 7. Detail of shredded melt-blown fabric. Experiment C. The white bar indicates $1 \mathrm{~mm}$. 


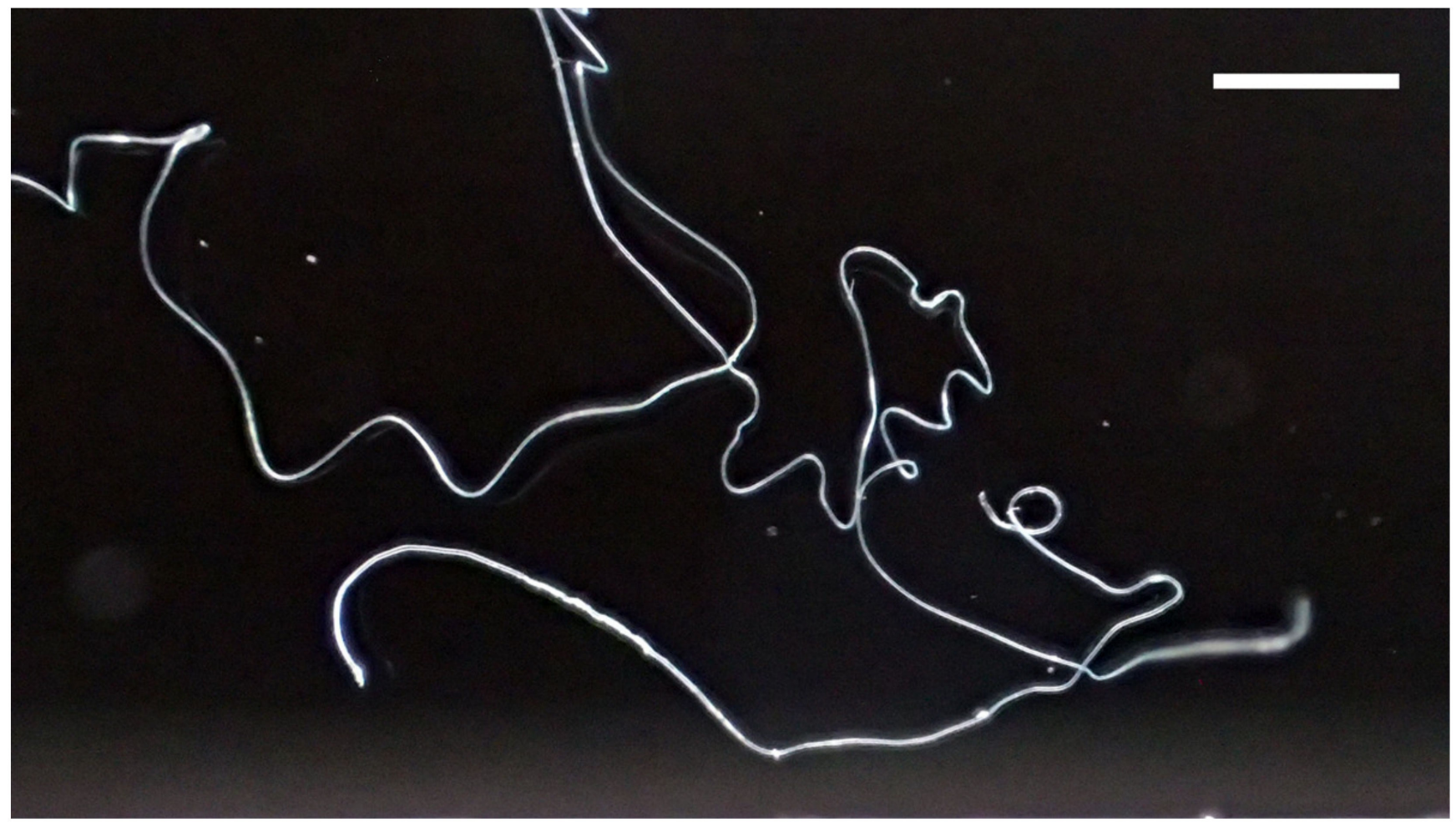

Figure 8. Detail of fibers of spunbond fabric. Experiment B. The white bar indicates $1 \mathrm{~mm}$.

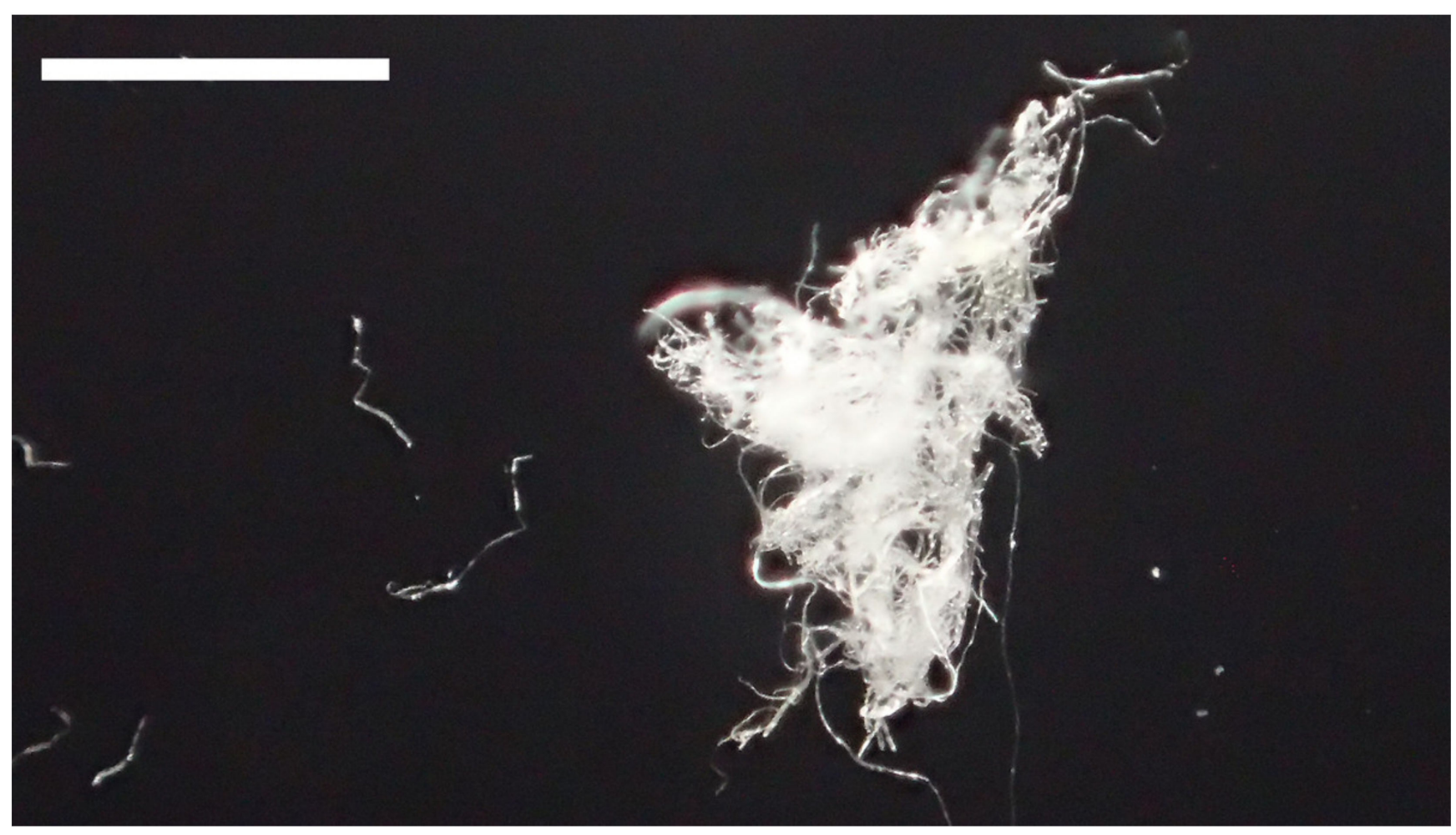

Figure 9. Detail of fibers of melt-blown fabric. Experiment B. The white bar indicates $1 \mathrm{~mm}$.

\section{Discussion}

The experiments have shown that lawn cutting equipment will shred discarded surgical-type single-use face masks in several larger and smaller pieces, some of which will be left behind on the surface, while others will be caught in leaf catchers. The height of the 
mower above the lawn and the length of the lawn pre mowing has a direct influence on the fragmentation of the masks.

The resulting lawn clippings and leaf waste will be either placed on personal compost heaps or will enter the municipal waste stream.

While household waste separation into recyclable hard waste (i.e., paper, aluminum, plastics) and solid waste destined for landfill is standard procedure among most local government councils, some councils deploy separate bins for the collection of green waste/organic waste (e.g., food remains, garden waste, lawn clippings), in addition to green waste collection from industry, such as landscaping businesses [45,46]. At the waste management center, the green waste is shredded or ground and composted for a set period [47], after which it is sold as garden mulch or as 'manufactured soil' [48,49], which is widely and frequently used in land reclamation and remediation projects [50-52].

While studies have considered the chemical composition and energy content as well as the particle size of urban household-derived green waste [53,54], the implications of microplastics have not been examined, although they have been foreshadowed as an emergent issue of concern [55]. Green waste arriving at waste management centers is manually sorted and larger inorganic items are extracted [56,57]. There is no indication as to the size of particles that are removed in these processes. As they are manual, it can be posited that macroplastics of $20 \mathrm{~mm}$ size and less will not be captured, unless bright coloring of the object acts as visual cue.

As noted in the experiment, about $75 \%$ of all pieces of SUM caught in the catcher belonged to the sizes below $10 \mathrm{~mm}^{2}$, many of which adhered to the lawn clippings. In a municipal sorting situation, in all reality, these items will escape detection and will continue through the processing stream. Further, larger pieces and possibly even entire masks, may escape detection, especially when saturated and dirtied (Figure S17).

While the environmental decay of polypropylene objects is slowed down dramatically once the item is buried and no longer exposed to ultraviolet radiation [20,23], the processing of green waste is such that shredded waste is arranged in open air windrows, which are regularly turned over for aeration [47]. In consequence, buried pieces of polypropylene fabric are likely to become exposed to ultraviolet radiation, at least on an intermittent basis.

The initial shredding and grinding process, followed by regular mixing in windrows and subsequent stockpiling, both at the waste management facility and later at the wholesaler, ensures that decaying pieces of polypropylene fabric are not only subject to ultraviolet radiation, but also to mechanical impacts and through mixing with non-contaminated matrix. The end user then spreads the manufactured soil on the property ensuring spatial dispersal.

The use of polypropylene for the manufacture of SUM is problematic, given that polypropylene does not decay per se. With UV light and mechanical impacts, including thermal expansion and contraction, the bonds between polypropylene fibers of both spunbond and melt-blown will weaken, resulting in the separation of individual fibers. UV light leads to embrittlement and fragmentation of the fibers into microplastics that will persist. While at present there appears to be little understanding on the longevity of these polypropylene-derive micro- and nanoplastics, it can be measured in decades if not centuries.

As noted by the study into future regulation of green waste management [55] the control of microplastic contamination will become a major regulatory issue. From a municipal environmental management perspective, it is imperative that a solution is found, and espoused sooner rather than later. The solutions are both on a manufacturing and supply level and on local property and land management level.

On the larger scale level, the manufacture of polypropylene-based SUM should be phased out in favor of SUM manufactured from biodegradable polymers [58,59]. That may require the adjustment of manufacturing techniques to ensure that the new fabrics have the same filtering capabilities. Beyond the immediacy of replacing current SUM with those made from biodegradable polymers, a caveat remains. The long-term effect of 
non-persistent micro-plastics from, at least theoretically, biodegradable polymers in the environment is not clear [60].

On the property and land management level such solutions should in the first instance entail a public information campaign that educates lawn mowing contractors as well as homeowners about the impact of these microplastics on the environment. Most will not be aware that microplastics are released from shredded fabric in the first place. Moreover that release is not limited to the site of destruction, but there is also the delayed and spatially much more distributed release once the pieces of shredded fabric exit the municipal green waste management stream. The preventative solution is simple: stopping the mower and picking of the SUM. It is appreciated that this will cause an impost for commercial contractors paid per job or on hourly rates.

Clearly, once shredded, masks and their smaller fragments-let alone the microfibersare out of sight and out of mind, but they are not out of the environment and will come to haunt us for generations to come.

\section{Conclusions}

As observations and experimental data have shown, lost or discarded surgical-type single-use face masks when impacted by lawn cutting equipment, are shredded into numerous pieces due to the low tensile strength of the constituent fabrics. The majority of these pieces are fragments of melt-blown fabric in the sub $10 \mathrm{~mm}^{2}$ range, most of which are captured in the leaf catcher of the lawn mower (if a catcher was fitted at the time of mowing). Given the emphasis of many local governments on green waste management, these pieces will end up in the organic waste stream, where waste management processes will further fragment them and mix them, with hitherto uncontaminated material. The resulting manufactured soil will contain a plethora of small macro items as well as well as micro-fibers and microplastics, which will be distributed to end users and will end up in municipal and as well as private landscaping. Future studies will provide the opportunity to assess the admixture and dispersal rates of small polymer-derived fabric during $g$ the wind rowing of green waste and the subsequent artificial soil production process (when sand and clay is added). A further line of investigation is the assessment of break-down of and microfiber generation by spunbond and melt-blown fabrics under controlled experimental conditions that realistically simulate mechanical shredding and subsequent break-down of fabric due to mechanical mixing and ultraviolet radiation.

In the meantime, public education strategies need to be deployed to prevent masks from entering into future waste management streams.

Supplementary Materials: The following are available online at https:/ / www.mdpi.com/article/ 10.3390/su14010207/s1. Figure S1. A non-sterile single-use surgical type mask on a head form. Figure S2. A non-sterile single-use surgical type mask manufactured in March 2020 by Shandong Shengningkang Medical Supplies Co, Dezhaou City, Shandong, China. Figure S3. Fabric used for the surgical-type single-use face mask shown in Figure S2. Figure S4. Fabric used for a surgicaltype single-use face mask shown in Figure S2. Figure S5. Example of disposable masks entering stormwater drains and water ways (various locations, Albury, NSW). Figure S6. Example of a shredded disposable mask on a roadside verge mowed by a council contractor (North Street, Albury, NSW). Figure S7. Example of a shredded disposable mask on a roadside verge mowed by a council contractor (North Street, Albury, NSW). Figure S8. Example of a shredded disposable mask on a roadside verge mowed by a council contractor (Elizabeth Mitchell Drive, Thurgoona, Albury, NSW). Figure S9. Example of a shredded disposable mask on a sporting field mowed by a club contractor (David Street, Albury, NSW). Figure S10. Example of a shredded disposable mask on a sporting field mowed by a club contractor (Macauley Street, Albury, NSW Street, Albury, NSW). Figure S11. Example of a shredded disposable mask on a footpath mowed by a local contractor (Poole Street, Albury, NSW. Figure S12. Example of a shredded disposable mask on a residential nature strip mowed by a resident (Alma Street, Albury, NSW). Figure S13. Example of a shredded disposable mask on a residential nature strip mowed by a resident (Alma Street, Albury, NSW). Figure S14. Examples of shredded disposable masks. Figure S15. Example of a shredded disposable mask on a 
residential nature strip mowed by a council contractor (Pemberton Street, Albury, NSW). The core area of distribution measures $4 \times 13 \mathrm{~m}$, with one piece located 20 apart. Figure S16. Example of a shredded disposable mask on a residential nature strip mowed by a resident (Alma Street, Albury, NSW). Figure S17. Examples of a saturated and dirtied disposable masks in urban settings (Alma Street, Albury, NSW). Figure S18. Experiment C being conducted. Screen capture of video. Figure S19. Experiment A. Remains of the mask. Main piece. Figure S20. Experiment A. Remains of the mask. small pieces. a) on lawn; b) in catcher. Figure S21. Experiment B. Remains of the mask. Main piece. Figure S22. Experiment C. Remains of the mask. Main piece. Figure S23. Experiment C. Remains of the mask. small pieces on lawn. Figure S24. Experiment C. Remains of the mask. small pieces in catcher.

Funding: This research received no external funding.

Institutional Review Board Statement: Not applicable.

Informed Consent Statement: Not applicable.

Data Availability Statement: Data sharing not applicable.

Conflicts of Interest: The author declares no conflict of interest.

\section{References}

1. WHO. Naming the Coronavirus Disease (COVID-19) and the Virus That Causes It. Available online: https://www.who.int/ emergencies / diseases / novel-coronavirus-2019/technical-guidance/naming-the-coronavirus-disease-(covid-2019)-and-thevirus-that-causes-it (accessed on 10 August 2020).

2. Stadnytskyi, V.; Anfinrud, P.; Bax, A. Breathing, speaking, coughing or sneezing: What drives transmission of SARS-CoV-2? J. Intern. Med. 2021, 21, 16. [CrossRef] [PubMed]

3. Gorbunov, B. Aerosol particles generated by coughing and sneezing of a SARS-CoV-2 (COVID-19) host travel over $30 \mathrm{~m}$ distance. Aerosol Air Qual. Res. 2021, 21, 200468. [CrossRef]

4. Karaivanov, A.; Lu, S.E.; Shigeoka, H.; Chen, C.; Pamplona, S. Face masks, public policies and slowing the spread of COVID-19: Evidence from Canada. J. Health Econ. 2021, 78, 102475. [CrossRef] [PubMed]

5. Cherry, T.L.; James, A.G.; Murphy, J. The impact of public health messaging and personal experience on the acceptance of mask wearing during the COVID-19 pandemic. J. Econ. Behav. Organ. 2021, 187, 415-430. [CrossRef]

6. Guy, G.P., Jr.; Lee, F.C.; Sunshine, G.; McCord, R.; Howard-Williams, M.; Kompaniyets, L.; Dunphy, C.; Gakh, M.; Weber, R.; Sauber-Schatz, E. Association of state-issued mask mandates and allowing on-premises restaurant dining with county-level COVID-19 case and death growth rates-United States, 1 March-31 December 2020. Morb. Mortal. Wkly. Rep. 2021, 70, 350.

7. MacIntyre, C.R.; Nguyen, P.-Y.; Chughtai, A.A.; Trent, M.; Gerber, B.; Steinhofel, K.; Seale, H. Mask use, risk-mitigation behaviours and pandemic fatigue during the COVID-19 pandemic in five cities in Australia, the UK and USA: A cross-sectional survey. Int. J. Infect. Dis. 2021, 106, 199-207. [CrossRef]

8. Prata, J.C.; Silva, A.L.P.; Duarte, A.C.; Rocha-Santos, T. Disposable over Reusable Face Masks: Public Safety or Environmental Disaster? Environments 2021, 8, 31. [CrossRef]

9. Kournikakis, B.; Harding, R.K.; Tremblay, J.; Simpson, M. Comparison of protection factors for selected medical, industrial and military masks. Appl. Biosaf. 2000, 5, 12-18. [CrossRef]

10. Cherrie, J.W.; Apsley, A.; Cowie, H.; Steinle, S.; Mueller, W.; Lin, C.; Horwell, C.J.; Sleeuwenhoek, A.; Loh, M. Effectiveness of face masks used to protect Beijing residents against particulate air pollution. Occup. Environ. Med. 2018, 75, 446-452. [CrossRef]

11. Coclite, D.; Napoletano, A.; Gianola, S.; Del Monaco, A.; D’Angelo, D.; Fauci, A.; Iacorossi, L.; Latina, R.; La Torre, G.; Mastroianni, C.M. Face mask use in the community for reducing the spread of COVID-19: A systematic review. Front. Med. 2020, 7, 594269. [CrossRef]

12. Park, C.-Y.; Kim, K.; Roth, S. Global Shortage of Personal Protective Equipment Amid COVID-19: Supply Chains, Bottlenecks, and Policy Implications; Asian Development Bank: Tokyo, Japan, 2020.

13. MedicalXpress. China Exported More Than 220 Billion Masks in 2020: Government. Available online: https://medicalxpress. $\mathrm{com} /$ news/2021-01-china-exported-billion-masks.html (accessed on 15 December 2021).

14. Adanur, S.; Jayswal, A. Filtration mechanisms and manufacturing methods of face masks: An overview. J. Ind. Text. 2020, 1-35. [CrossRef]

15. Midha, V.K.; Dakuri, A.; Midha, V. Studies on the properties of nonwoven surgical gowns. J. Ind. Text. 2013, 43, 174-190. [CrossRef]

16. Chua, M.H.; Cheng, W.; Goh, S.S.; Kong, J.; Li, B.; Lim, J.Y.; Mao, L.; Wang, S.; Xue, K.; Yang, L. Face masks in the new COVID-19 normal: Materials, testing, and perspectives. Research 2020, 2020, 7286735. [CrossRef]

17. Sales, E.; Mulatier, N.; Wittmann, L.; Fernandes, A.; Vacher, B.; Penuelas, J. Effect of dry heat treatment between room temperature and $160{ }^{\circ} \mathrm{C}$ on surgical mask. Mater. Lett. 2021, 308, 131270. [CrossRef] 
18. Wang, D.; Sun, B.-C.; Wang, J.-X.; Zhou, Y.-Y.; Chen, Z.-W.; Fang, Y.; Yue, W.-H.; Liu, S.-M.; Liu, K.-Y.; Zeng, X.-F. Can masks be reused after hot water decontamination during the COVID-19 pandemic? Engineering 2020, 6, 1115-1121. [CrossRef]

19. Rajakumar, K.; Sarasvathy, V.; Chelvan, A.T.; Chitra, R.; Vijayakumar, C. Natural weathering studies of polypropylene. J. Polym. Environ. 2009, 17, 191-202. [CrossRef]

20. Shimizu, K.; Tokuta, Y.; Oishi, A.; Kuriyama, T.; Kunioka, M. Weatherability of polypropylene by accelerated weathering tests and outdoor exposure tests in Japan. J. Polym. 2016, 2016, 1-14. [CrossRef]

21. Yang, X.; Ding, X. Prediction of outdoor weathering performance of polypropylene filaments by accelerated weathering tests. Geotext. Geomembr. 2006, 24, 103-109. [CrossRef]

22. Saliu, F.; Veronelli, M.; Raguso, C.; Barana, D.; Galli, P.; Lasagni, M. The release process of microfibers: From surgical face masks into the marine environment. Environ. Adv. 2021, 4, 100042. [CrossRef]

23. Lv, Y.; Huang, Y.; Kong, M.; Yang, Q.; Li, G. Multivariate correlation analysis of outdoor weathering behavior of polypropylene under diverse climate scenarios. Polym. Test. 2017, 64, 65-76. [CrossRef]

24. Andrady, A.; Pegram, J.; Tropsha, Y. Changes in carbonyl index and average molecular weight on embrittlement of enhancedphotodegradable polyethylenes. J. Environ. Polym. Degrad. 1993, 1, 171-179. [CrossRef]

25. Nam, S.; Slopek, R.; Wolf, D.; Warnock, M.; Condon, B.D.; Sawhney, P.; Gbur, E.; Reynolds, M.; Allen, C. Comparison of biodegradation of low-weight hydroentangled raw cotton nonwoven fabric and that of commonly used disposable nonwoven fabrics in aerobic Captina silt loam soil. Text. Res. J. 2016, 86, 155-166. [CrossRef]

26. Chamas, A.; Moon, H.; Zheng, J.; Qiu, Y.; Tabassum, T.; Jang, J.H.; Abu-Omar, M.; Scott, S.L.; Suh, S. Degradation rates of plastics in the environment. ACS Sustain. Chem. Eng. 2020, 8, 3494-3511. [CrossRef]

27. Benson, N.U.; Bassey, D.E.; Palanisami, T. COVID pollution: Impact of COVID-19 pandemic on global plastic waste footprint. Heliyon 2021, 7, e06343. [CrossRef]

28. Yousefi, M.; Oskoei, V.; Jafari, A.J.; Farzadkia, M.; Firooz, M.H.; Abdollahinejad, B.; Torkashvand, J. Municipal solid waste management during COVID-19 pandemic: Effects and repercussions. Environ. Sci. Pollut. Res. 2021, 28, 1-10. [CrossRef]

29. Topal, M.; Arslan Topal, E.I. Determination of the Estimated Amounts of Discarded Face Masks due to COVID 19 in Turkey. Pollution 2021, 7, 573-584.

30. Mejjad, N.; Cherif, E.K.; Rodero, A.; Krawczyk, D.A.; El Kharraz, J.; Moumen, A.; Laqbaqbi, M.; Fekri, A. Disposal Behavior of Used Masks during the COVID-19 Pandemic in the Moroccan Community: Potential Environmental Impact. Int. J. Environ. Res. Public Health 2021, 18, 4382. [CrossRef]

31. France, R.L. First landscape-scale survey of the background level of COVID-19 face mask litter: Exploring the potential for citizen science data collection during a 'pollution pilgrimage' of walking a 250-km roadside transect. Sci. Total Environ. 2021, 151569. (in press). [CrossRef]

32. Okuku, E.; Kiteresi, L.; Owato, G.; Otieno, K.; Mwalugha, C.; Mbuche, M.; Gwada, B.; Nelson, A.; Chepkemboi, P.; Achieng, Q. The impacts of COVID-19 pandemic on marine litter pollution along the Kenyan Coast: A synthesis after 100 days following the first reported case in Kenya. Mar. Pollut. Bull. 2021, 162, 111840. [CrossRef]

33. Ormaza-González, F.; Castro-Rodas, D. COVID-19 Impacts on Beaches and Coastal Water Pollution: Management Proposals Post-pandemic. Preprints 2020, 1, 2020060186. [CrossRef]

34. Shruti, V.; Pérez-Guevara, F.; Elizalde-Martínez, I.; Kutralam-Muniasamy, G. Reusable masks for COVID-19: A missing piece of the microplastic problem during the global health crisis. Mar. Pollut. Bull. 2020, 161, 111777. [CrossRef] [PubMed]

35. Wang, Z.; An, C.; Chen, X.; Lee, K.; Zhang, B.; Feng, Q. Disposable masks release microplastics to the aqueous environment with exacerbation by natural weathering. J. Hazard. Mater. 2021, 417, 126036. [CrossRef] [PubMed]

36. Fadare, O.O.; Okoffo, E.D. Covid-19 face masks: A potential source of microplastic fibers in the environment. Sci. Total Environ. 2020, 737, 140279. [CrossRef] [PubMed]

37. Neto, H.G.; Bantel, C.G.; Browning, J.; Della Fina, N.; Ballabio, T.A.; de Santana, F.T.; e Britto, M.d.K.; Barbosa, C.B. Mortality of a juvenile Magellanic penguin (Spheniscus magellanicus, Spheniscidae) associated with the ingestion of a PFF-2 protective mask during the Covid-19 pandemic. Mar. Pollut. Bull. 2021, 166, 112232. [CrossRef]

38. Silva, A.L.P.; Prata, J.C.; Mouneyrac, C.; Barcelò, D.; Duarte, A.C.; Rocha-Santos, T. Risks of Covid-19 face masks to wildlife: Present and future research needs. Sci. Total Environ. 2021, 792, 148505. [CrossRef]

39. Hiemstra, A.-F.; Rambonnet, L.; Gravendeel, B.; Schilthuizen, M. The effects of COVID-19 litter on animal life. Anim. Biol. 2021, 71, 215-231. [CrossRef]

40. Spennemann, D.H.R. Curating the Contemporary: A case for national and local COVID-19 collections. Curator 2022, 65. [CrossRef]

41. Spennemann, D.H.R. Patterns of a Pandemic. In A Documentation of COVID-19 Masks Sold, Lost and Discarded in a Regional Australian City; Institute for Land, Water and Society Report 164; Institute for Land, Water and Society, Charles Sturt University: Albury, NSW, Australia, 2021.

42. Spennemann, D.H.R. Facing COVID-19: Quantifying the use of reusable vs. disposable facemasks. Hygiene 2021, 1, 11. [CrossRef]

43. Spennemann, D.H.R. A Rapid Observational Survey of Face Mask Use in a Major Shopping Centre in Melbourne (Victoria); Institute for Land, Water and Society, Charles Sturt University: Albury, NSW, Australia, 2021.

44. Spennemann, D.H.R. COVID face masks: Policy shift results in increased littering. Sustainability 2021, 13, 9875. [CrossRef]

45. Zamri, G.B.; Azizal, N.K.A.; Nakamura, S.; Okada, K.; Nordin, N.H.; Othman, N.; Akhir, F.N.M.; Sobian, A.; Kaida, N.; Hara, H. Delivery, impact and approach of household food waste reduction campaigns. J. Clean. Prod. 2020, 246, 118969. [CrossRef] 
46. Herron, M.; Jones, D.S.; Roös, P.B.; Allam, Z. Creating Revenue Out Of Green Waste: New Perspectives For Municipal Organic Waste Harvesting In Geelong, Australia. Geogr. Environ. Sustain. 2021, 14, 91-105. [CrossRef]

47. SUEZ Australia. Organic Resource Recovery Facilities. Fact Sheet Recycling \& Recovery. Available online: https://www.suez. com.au/en-au/who-we-are/suez-in-australia-and-new-zealand/our-facilities/organic-resource-recovery-facilities (accessed on 20 November 2021).

48. Belyaeva, O.N.; Haynes, R.J. Chemical, microbial and physical properties of manufactured soils produced by co-composting municipal green waste with coal fly ash. Bioresour. Technol. 2009, 100, 5203-5209. [CrossRef]

49. Belyaeva, O.N.; Haynes, R.J. A comparison of the properties of manufactured soils produced from composting municipal green waste alone or with poultry manure or grease trap/septage waste. Biol. Fertil. Soils 2010, 46, 271-281. [CrossRef]

50. Haigh, M.; Desai, M.; Cullis, M.; D’Aucourt, M.; Sansom, B.; Wilding, G.; Alun, E.; Garate, S.; Hatton, L.; Kilmartin, M. Composted municipal green waste enhances tree success in opencast coal land reclamation in Wales. Air Soil Water Res. 2019, 12, 1178622119877837. [CrossRef]

51. McCullough, C.D.; Lund, M.A.; May, J.M. Microcosm testing of municipal sewage and green waste for full-scale remediation of an acid coal pit lake, in semi-arid tropical Australia. In Proceedings of the 7th International Conference on Acid Rock Drainage, St. Louis, MO, USA, 26-30 March 2006.

52. Shekhada, D. Utilization Strategy and Management of Green Waste to Improve Wasteland Fertility in Australia. Int. J. Environ. Agric. Biotechnol. 2019, 4, 64-68. [CrossRef]

53. Roberts, D. Characterisation of chemical composition and energy content of green waste and municipal solid waste from Greater Brisbane, Australia. Waste Manag. 2015, 41, 12-19.

54. Haynes, R.; Belyaeva, O.; Zhou, Y.-F. Particle size fractionation as a method for characterizing the nutrient content of municipal green waste used for composting. Waste Manag. 2015, 35, 48-54. [CrossRef]

55. Wilkinson, K.; Price, J.; Biala, J.; McDonald, D. Review of Regulations and Standards for Recycled Organics in Australia. In Final Report for Department of Agriculture, Water and Environment; Department of Agriculture, Water and the Environment: Canberra, Australia, 2021.

56. WM Waste Management Services. What Happens to Green Waste After It's Been Collected. Available online: https://www. wmwaste.com.au/resource-centre/what-happens-to-green-waste-after-its-been-collected/ (accessed on 20 November 2021).

57. SUEZ Australia. Food \& Garden Organics. Available online: https://www.suez.com.au/en-au/sustainability-tips/learn-aboutwaste-streams / general-waste-streams/organic-waste-and-green-waste-removal (accessed on 20 November 2021).

58. Wibisono, Y.; Fadila, C.R.; Saiful, S.; Bilad, M.R. Facile approaches of polymeric face masks reuse and reinforcements for micro-aerosol droplets and viruses filtration: A review. Polymers 2020, 12, 2516. [CrossRef]

59. Das, O.; Neisiany, R.E.; Capezza, A.J.; Hedenqvist, M.S.; Försth, M.; Xu, Q.; Jiang, L.; Ji, D.; Ramakrishna, S. The need for fully bio-based facemasks to counter coronavirus outbreaks: A perspective. Sci. Total Environ. 2020, 736, 139611. [CrossRef]

60. Haider, T.P.; Völker, C.; Kramm, J.; Landfester, K.; Wurm, F.R. Plastics of the future? The impact of biodegradable polymers on the environment and on society. Angew. Chem. Int. Ed. 2019, 58, 50-62. [CrossRef] 